\title{
Modification of Tobacco rattle virus RNA1 to Serve as a VIGS Vector Reveals That the 29K Movement Protein Is an RNA Silencing Suppressor of the Virus
}

\author{
Xianbao Deng, Jani Kelloniemi, Tuuli Haikonen, Anssi L. Vuorinen, Paula Elomaa, Teemu H. Teeri, and \\ Jari P. T. Valkonen
}

Department of Agricultural Sciences, P.O. Box 27, Fl-00014 University of Helsinki, Finland

Submitted 2 December 2012. Accepted 19 January 2013.

\begin{abstract}
Tobacco rattle virus (TRV) has a bipartite, positive-sense single-stranded RNA genome and is widely used for virusinduced gene silencing (VIGS) in plants. RNA1 of TRV that lacks the gene for the cysteine-rich $16 \mathrm{~K}$ silencing-suppression protein infects plants systemically in the absence of RNA2. Here, we attempted to engineer RNA1 for use as a VIGS vector by inserting heterologous gene fragments to replace $16 K$. The RNA1 vector systemically silenced the phytoene desaturase (PDS) gene, although less efficiently than when the original VIGS vector system was used, which consists of wild-type RNA1 and engineered RNA2 carrying the heterologous gene. Infectious RNA1 mutants with a dysfunctional $16 K$ suppressed silencing and enhanced transgene expression in green fluorescent protein-transgenic Nicotiana benthamiana following inoculation by agroinfiltration, unlike mutants that also lacked $29 \mathrm{~K}$, a movement protein (MP) gene. The 30K MP gene of Tobacco mosaic virus complemented in cis the movement defect but not the silencing suppression functions of TRV 29K. Silencing suppression by $29 \mathrm{~K}$ occurred in the context of RNA1 replication but not in an agroinfiltration assay which tested 29K alone for suppression of sense-mediated silencing. Both $29 \mathrm{~K}$ and $16 \mathrm{~K}$ were needed to avoid necrotic symptoms in RNA1-infected $N$. benthamiana. The results shed new light on virulence factors of TRV.
\end{abstract}

Tobacco rattle virus (TRV) has a bipartite, positive-sense single-stranded RNA (ssRNA) genome and is a type member of the genus Tobravirus (family Virgaviridae) (Adams et al. 2012). RNA1 contains four open reading frames (ORF), one of which encodes a $194 \mathrm{~K}$ protein, including the methyltransferase, helicase, and RNA-dependent RNA polymerase (RdRp) domains, and is translated from the genomic RNA (Hamilton et al. 1987; MacFarlane 1999). The $29 \mathrm{~K}$ and $16 \mathrm{~K}$ proteins are translated from the respective subgenomic RNAs (sgRNA) and function as

Current address for J. Kelloniemi: INRA Dijon-IPM, 17 Rue Sully, BP 86510, 21065 Dijon cedex, France.

Current address for A. Vuorinen: Department of Biochemistry and Food Chemistry, Vatselankatu 2, FI-20014 University of Turku, Finland.

Corresponding author: J. P. T. Valkonen; Telephone: +358-9-19158387; Fax: +358-9-19158727; E-mail: jari.valkonen@ @elsinki.fi

* The $\boldsymbol{e}$-Xtra logo stands for "electronic extra" and indicates that four supplementary figures and one supplementary table are published online.

(C) 2013 The American Phytopathological Society a movement protein (MP) (Hamilton and Baulcombe 1989) and a suppressor of RNA silencing (Ghazala et al. 2008; MartínHernández and Baulcombe 2008; Martínez-Priego et al. 2008; Reavy et al. 2004), respectively. RNA silencing is a basal cellular antiviral defense mechanism that targets double-stranded RNA, including the replicative forms of viral RNA (Wu et al. 2010). TRV RNA2 can vary in size and gene content but always encodes a coat protein (CP), which encapsidates RNA1 and RNA2 into different rod-shaped particles (Cornelissen et al. 1986; Hamilton et al. 1987; MacFarlane 1999). RNA2 also encodes the proteins $2 \mathrm{~b}$ and $2 \mathrm{c}$, which are implicated in transmission of TRV by root nematodes (Hernández et al. 1997; MacFarlane et al. 1999), and $2 \mathrm{~b}$ also in invasion of meristems in roots (Valentine et al. 2004). All proteins encoded by RNA2 are translated from sgRNAs (MacFarlane 1999). TRV does not require $\mathrm{CP}$ and viral particles for viral long-distance movement in plants and, hence, systemic infection with RNA1 alone can occur (Swanson et al. 2002).

Infectious cDNA clones of TRV are used as tools for functional genomic studies on plants (MacFarlane 2010). For virusinduced gene silencing (VIGS), $2 b$ and $2 c$ are removed from RNA2, and a convenient multiple cloning site is engineered to facilitate insertion of the target plant gene or its fragment (Liu et al. 2002b; Ratcliff et al. 2001; Ruiz et al. 1998). The Cauliflower mosaic virus (CaMV) 35S promoter-driven cDNAs of RNA1 and RNA2 have been cloned into binary vectors, transformed into Agrobacterium, and introduced into plants by agroinfection (Grimsley et al. 1986) by, for example, infiltration of leaves (Kapila et al. 1997) or tooth-pick inoculation of stems with agrobacteria (Elmer et al. 1988). As the infection spreads, the replicating VIGS vector, which includes the plantderived sequence, is targeted by Dicers (DCL) that recognize long double-stranded RNA and cleave it into small interfering RNAs (siRNAs) (21 to 24 nucleotides [nt]) (Xie et al. 2004). siRNAs bind to and guide the cellular ssRNA-specific RNases (Argonaute [AGO]) to cleave the homologous ssRNA molecules (i.e., the VIGS vector) and the plant mRNA that is homologous to the insert. The use of VIGS vectors enables rapid inoculation of a large number of plants and high-throughput examination of gene functions (Deng et al. 2012; SenthilKumar and Mysore 2011).

A VIGS vector should have rapid replication and systemic movement in plants to be an efficient gene-silencing tool. The vector virus also needs to circumvent RNA silencing to cause systemic infection and uniformly invade plant tissues but it should not suppress RNA silencing too efficiently, because that would negatively affect gene silencing. TRV is a preferred VIGS vector because it has a wide host range and is able to 
invade meristems (Martín-Hernández and Baulcombe 2008; Robinson and Harrison 1989), which allows gene silencing at early stages of organ development. However, as with viruses in general, infection with TRV-based VIGS vectors is dependent on the host genotype. For example, many potato (Solanum tuberosum) and tobacco (Nicotiana tabacum) varieties express various types of resistance to TRV infection or respond to TRV infection with necrotic or other types of symptoms, hampering observation of gene-silencing phenotypes in the host (Brigneti et al. 2004; Ghazala and Varrelmann 2007; MacFarlane 2010; Peart et al. 2002). TRV-susceptible plant genotypes may be used to overcome the problem in some cases (Deng et al. 2012) but not for plant genotype-specific research (Senthil-

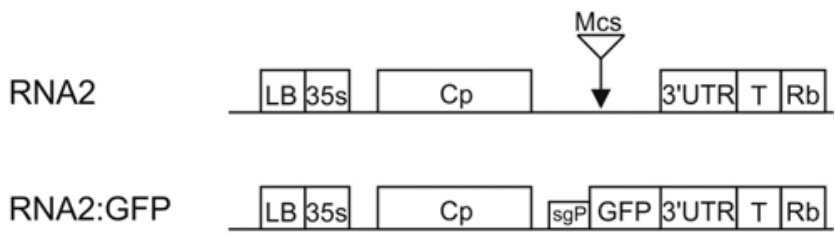

RNA1

\begin{tabular}{|c|c|c|c|}
\hline \begin{tabular}{|l|l|} 
LB & $35 \mathrm{~s}$ \\
\end{tabular} & RdRp & Mp 16k 3'UTR T & $\mathrm{Rb}$ \\
\hline
\end{tabular}

16 Kstop

M1

M2

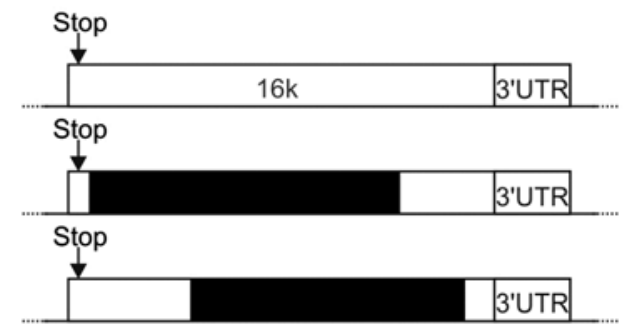

\begin{tabular}{|c|c|c|c|}
\hline \multirow[t]{2}{*}{ trv30K } & TMV-30K-MP & $16 \mathrm{k}$ & 3'UTR \\
\hline & \multicolumn{3}{|c|}{ Stop } \\
\hline trv30K16Kstop & TMV-30K-MP & $16 \mathrm{k}$ & $3^{\prime}$ UTR \\
\hline
\end{tabular}

Fig. 1. Schematic presentation of the T-DNA organization of plant binary transformation plasmids containing cDNA clones of Tobacco rattle virus (TRV) RNA1 and RNA2 and the TRV constructs made for this study. The viral cDNA clones, which include the $3^{\prime}$-untranslated region ( $3^{\prime}$ UTR), are positioned between the left and right border (LB and RB) of the T-DNA, and between the Cauliflower mosaic virus (CaMV) $35 \mathrm{~S}$ promoter (35s) and a transcriptional terminator (T). The TRV RNA2-based vector (pTV00) (Ratcliff et al. 2001) encodes a coat protein (CP), whereas the two genes involved in nematode transmission of TRV ( $2 b$ and $2 c$ ) have been removed and replaced with a multiple cloning site (Mcs). In RNA2:GFP, the gene for Aequoria victoriae GFP was inserted into the Mcs, and the $\mathrm{CP}$ subgenomic RNA promoter ( $\mathrm{sgP}$ ) derived from Pea early-browning virus has been added upstream of GFP (MacFarlane and Popovich 2000). The TRV RNA1-based vector pBINTRA6 (Ratcliff et al. 2001) was modified to contain the complete TRV RNA1 cDNA encoding the RNA-dependent RNA polymerase (RdRp), the $29 \mathrm{~K}$ movement protein (MP), and the $16 \mathrm{~K}$ protein (16k). In TRV, RdRp is translated from the genomic RNA, whereas $29 \mathrm{~K}$ and $16 \mathrm{~K}$ are translated from subgenomic RNAs (sgRNA1a and sgRNA1b, respectively). Five TRV RNA1 mutants were made based on pBINTRA6. 16Kstop, M1, and M2 carried a stop codon in the fourth codon of $16 \mathrm{~K}$. Furthermore, most of $16 \mathrm{~K}$ (426 nucleotides) was deleted in M1 (nucleotides 13 to 317) and M2 (nucleotides 151 to 401; deletions are indicated by black boxes). 16Kstop and M1 were similar to the mutants described by Guilford and associates (1991). In trv30K and trv30K16Kstop, all of $29 \mathrm{~K}$ was replaced by Tobacco mosaic virus (TMV) $30 \mathrm{~K}$. Similar to 16 Kstop, trv30K16Kstop carried a stop codon in the beginning of $16 \mathrm{~K}$.
Kumar and Mysore 2011). TRV RNA1 can also infect plants in the absence of RNA2, and the elimination of RNA2 may be escalated when RNA2 carries a host gene and becomes the prime target of silencing. Consequently, silencing of the target gene in systemically infected leaves may be aberrant.

The aim of this study was to test whether TRV RNA1 alone could be used as a VIGS vector carrying silencing-inducing foreign gene insertions in place of $16 K$. Partial or complete removal of $16 \mathrm{~K}$ does not prevent systemic movement of TRV (Guilford et al. 1991; Martín-Hernández and Baulcombe 2008). Furthermore, because $16 \mathrm{~K}$ is a suppressor of RNA silencing, replacement of $16 \mathrm{~K}$ with a heterologous gene was anticipated to enhance silencing. In an attempt to alleviate the necrotic symptoms induced by TRV in many tobacco and potato genotypes, we tested whether the TRV 29K MP, which elicits necrotic symptoms (Ghazala and Varrelmann 2007; Guilford et al. 1991), could be replaced with the $30 \mathrm{~K}$ MP of Tobacco mosaic virus (TMV), which complements in trans viral movement in 29K-defective TRV mutants (Ziegler-Graff et al. 1991) but whose functionality when integrated into TRV RNA1 has not been reported.

\section{RESULTS}

Disruption of TRV $16 \mathrm{~K}$ enhances necrotic symptoms.

Three RNA1 constructs were generated to prevent $16 \mathrm{~K}$ expression. A premature translation stop codon was introduced into $16 \mathrm{~K}$ by site-directed mutation of the fourth codon (GTA $\rightarrow$ TGA; mutant 16Kstop) (Fig. 1). Additionally, two deletions were made within $16 \mathrm{~K}$ of the $16 \mathrm{Kstop}$ mutant that removed either the $5^{\prime}$-proximal region $(72 \%$ of $16 K)$ or $3^{\prime}$-proximal part $(59 \%)$ downstream from the introduced premature stop codon (constructs M1 and M2, respectively) (Fig. 1). Construct M1 is identical to the previously described mutant pTR16D4 of TRV RNA1 (Guilford et al. 1991) and was compared with the new construct M2, in which the $5^{\prime}$-proximal part of the $16 \mathrm{~K} \mathrm{ORF}$ was retained. Agroinfiltration of leaves of $N$. benthamiana with M1, M2, and 16Kstop constructs induced necrotic symptoms that were most severe with $16 \mathrm{Kstop}$, whereas infiltration with wild-type RNA1 (wtRNA1) caused no necrosis (Fig. 2A, panel i). Quantitative reverse-transcription polymerase chain reaction (qRT-PCR) analysis indicated that the titers of wtRNA1 and mutants initially increased in the upper noninoculated leaves and subsequently declined (Supplementary Fig. S1). Concentrations of wtRNA1 reached the highest level at 7 days postinoculation (dpi), whereas the highest concentration of 16Kstop RNA1 was observed at 10 dpi. Systemic accumulation of M1 and M2 reached the highest level at 13 dpi. Although wtRNA1 caused no symptoms, 16Kstop induced severe malformation in the systemically infected leaves and stunting of the plants. M1 and M2 caused milder, albeit similar, symptoms (Fig. 2A, panels ii and iii). These and other experiments of this study generally showed similar results with M1 and M2 and, hence, M1 results are often shown to represent both constructs also in the following experiments.

Detection of wtRNA1, 16Kstop, and M1 in the systemically infected leaves by Northern blot hybridization revealed the expected RNA1, sgRNA1a, and sgRNA1b sizes which, in M1 (Fig. 3A) and M2, were shorter because of a deletion in $16 \mathrm{~K}$. At 7 dpi, these RNAs were detected only in plants inoculated with wtRNA1 (Fig. 3A) whereas, at 13 dpi, the corresponding RNAs of M1 (Fig. 3A) and M2 were present at higher titers than were those for wtRNA1, consistent with results obtained by qRT-PCR. These results indicated that there are 16K-dependent differences in the accumulation dynamics of the viruses in the systemically infected leaves.

Co-inoculation of leaves with the wtRNA1, M1, M2, or 16Kstop together with RNA2 ("empty vector") (Fig. 2B, panel 
i) induced symptoms in inoculated leaves similar to those observed with inoculation with RNA1 alone. However, symptoms in systemically infected leaves (Fig. 2B, panels ii and iii) were somewhat more severe. The mildest leaf symptoms (mosaic, mild chlorosis, and some epinasty) were caused by wtRNA1 + RNA2, with M1 and M2 causing more severe epinasty. 16Kstop induced the most severe symptoms, including vein necrosis, necrotic lesions, epinasty, and chlorosis, in the systemically infected leaves, and plants were stunted (Fig. 2B, panel iii). Symptoms in systemically infected leaves appeared 2 to 3 days earlier than those following inoculation with RNA1 alone, and accumulation of viral RNAs reached the highest concentrations 2 to 3 days earlier than following infection solely with RNA1 (Fig. 3B). Northern blot hybridization re-

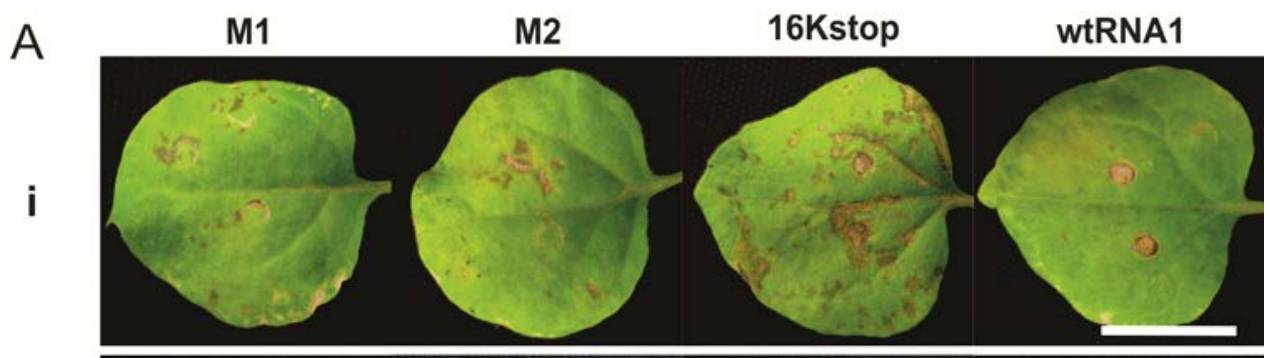

ii

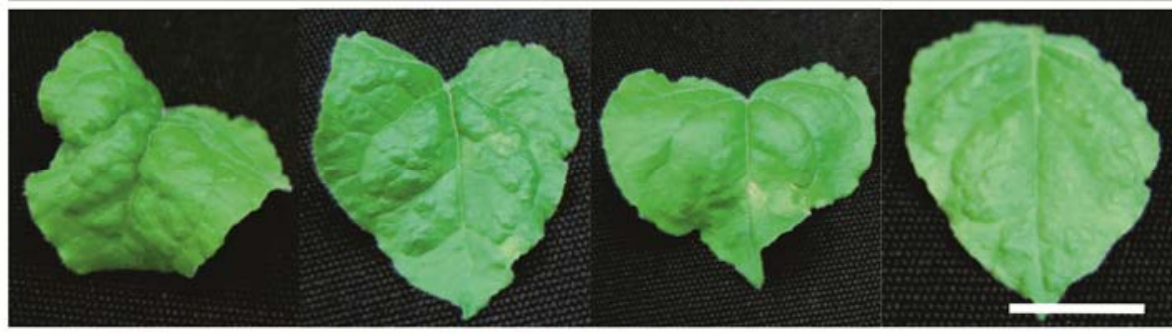

iii

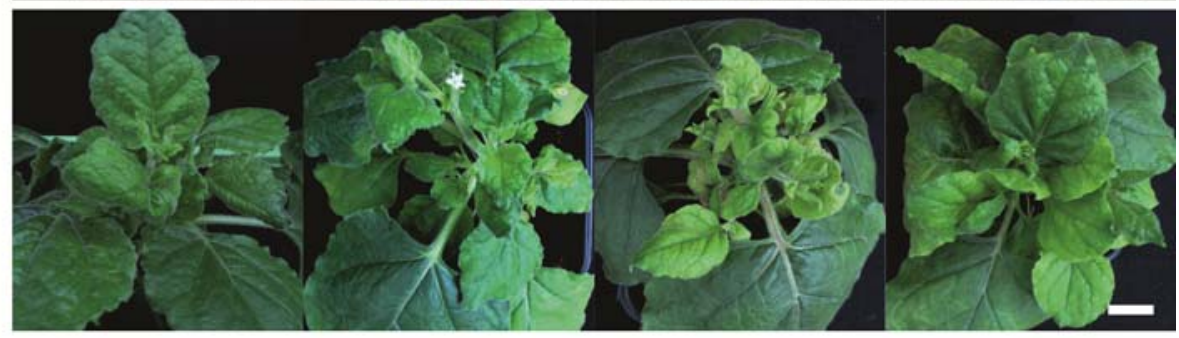

B
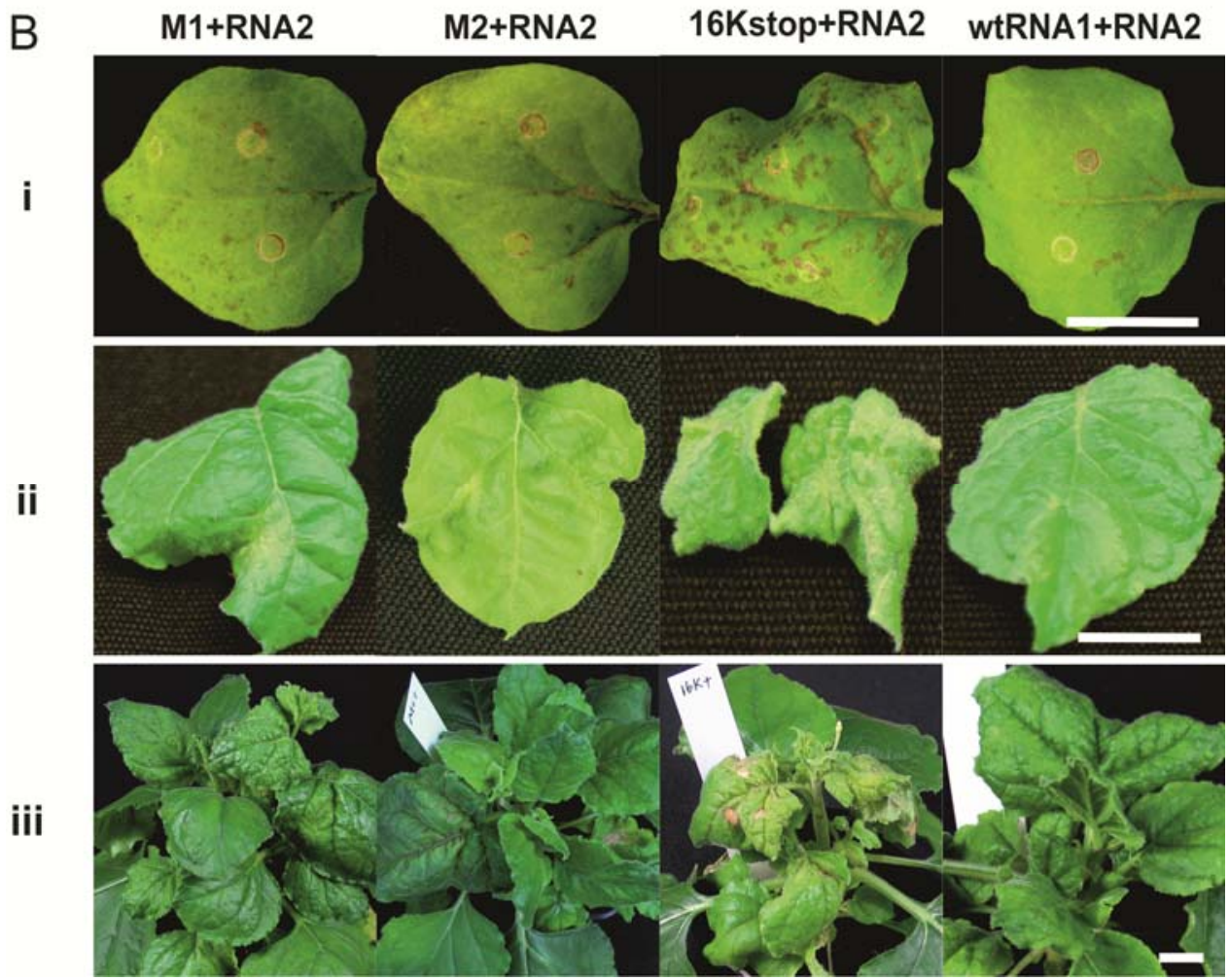

Fig. 2. Symptoms induced by Tobacco rattle virus (TRV) wild-type (wt)RNA1 and the RNA1 mutants M1, M2, and 16Kstop in Nicotiana benthamiana. A, Infections with RNA1 alone i) in the leaves inoculated by agroinfiltration and ii) in the systemically infected leaves 10 days postinoculation (dpi); and iii) an overall view of the morphology and symptoms at $15 \mathrm{dpi}$. B, Infections with RNA1 + RNA2 as shown in A. Bars in A and B indicate $2 \mathrm{~cm}$. 
vealed RNA1, sgRNA1a, sgRNA1b, and RNA2 in the systemically infected leaves of all inoculated plants at 7 and 13 dpi. The concentrations of M1 (and M2) RNA at 7 dpi were lower than those of wtRNA1 and 16Kstop, which were similar (Fig. 3B). These differences were in accordance with differences in the rate of systemic accumulation of wtRNA1 and the RNA1 mutants and, additionally, indicated that RNA2 enhanced systemic infection.

All of the aforementioned experiments were carried out three times independently with similar results. Mutations introduced into RNA1 were verified in the progeny viruses by RTPCR and sequencing of the products.

\section{Mutation of $16 \mathrm{~K}$ does not enhance VIGS.}

VIGS vectors M1:PDS and M2:PDS were generated by cloning a 200-bp fragment of the $N$. benthamiana phytoene desaturase (PDS) gene into the M1 and M2 constructs to replace the deleted part of $16 \mathrm{~K}$ (Fig. 1). Agroinfiltration of these constructs without RNA2 into leaves of $N$. benthamiana induced symptoms similar to those obtained with M1 and M2 in the infiltrated leaves. No visually detectable PDS silencing occurred until 30 dpi in three experiments.

Following agroinfiltration for expression of RNA2 together with M1:PDS (Fig. 4A) or M2:PDS, the systemically infected leaves became chlorotic and occasionally developed white "photobleached" tissues (Kumagai et al. 1995) along the veins (Supplementary Fig. S2). Expression levels of PDS mRNA were $65 \%$ in the chlorotic tissues as compared with the control. However, when wtRNA1 + RNA2:PDS was used, extensive photobleaching was observed in the systemically infected leaves, and PDS mRNA levels were only $4 \%$ of those detected in the control (Fig. 4A).

Subsequently, the M1, M2, 16Kstop, and wtRNA1 were coinoculated with RNA2:PDS into $N$. benthamiana (Fig. 4B). Infection with M1 + RNA2:PDS (Fig. 4B, panel i, leaf 1) and M2 + RNA2:PDS induced similar chlorosis and photobleached patches in the systemically infected leaves of most plants by 20 dpi, whereas 16Kstop + RNA2:PDS induced somewhat

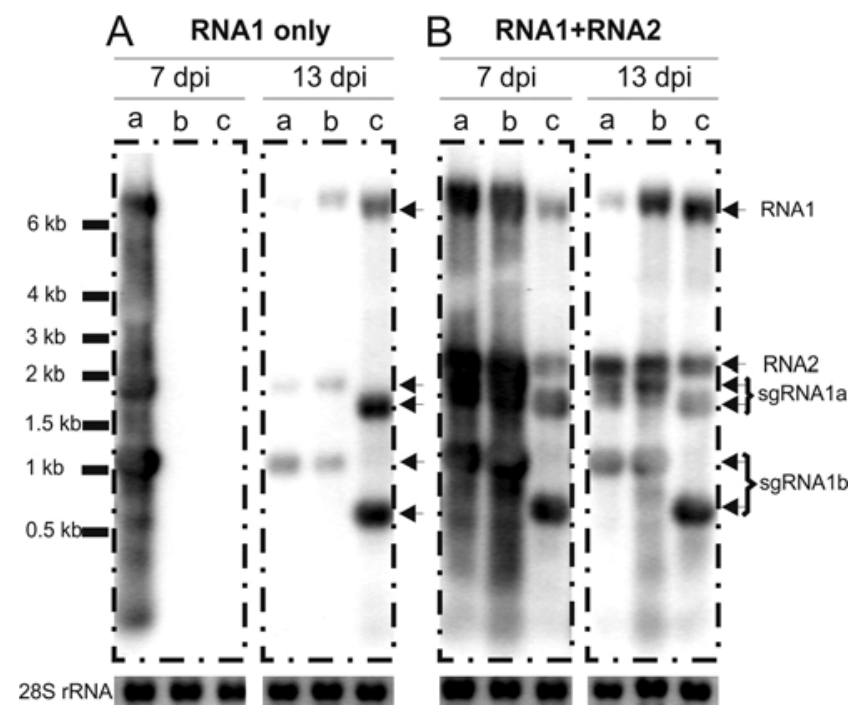

Fig. 3. Detection of Tobacco rattle virus (TRV) RNAs in the apical leaves of infected plants at 7 and 13 days postinoculation (dpi). The $3^{\prime}$ untranslated region is identical in RNA1 and RNA2 and was used as a probe to detect both genomic RNAs and all subgenomic ( $\mathrm{sg}$ )RNAs by Northern blot analysis. A, Infection with RNA1 alone. B, Infection with RNA1 + RNA2. In each panel: lane a, wild-type (wt)RNA1; lane b, 16Kstop; and lane c, M1. Note that RNA1, sgRNA1a, and sgRNA1b were shorter in M1 than wtRNA1 and $16 \mathrm{Kstop}$ because of deletion in the $16 \mathrm{~K}$ gene of M1. 28S rRNA, 28S ribosomal RNA used as a loading control. more extensive photobleaching in all infected plants (Fig. 4B, panel i, leaf 2). Infection with 16Kstop + RNA2:PDS also induced severe disease symptoms, including extensive necrosis in systemically infected leaves, at 20 dpi (Fig. 4B, panel i, leaf $\left.2^{\prime}\right)$. However, systemic infection with wtRNA1 + RNA2:PDS induced no necrosis (Fig. 4B, panel i, leaf $3^{\prime}$ ), although this combination caused the most extensive photobleaching among all constructs. qRT-PCR analysis showed that infection with M1 + RNA2:PDS, 16Kstop + RNA2:PDS, and wtRNA1 + RNA2:PDS decreased PDS mRNA levels to 43,37 , and $4 \%$, respectively, of the amounts detected in the leaves of noninoculated control plants (Fig. 4B, ii). Results were similar in three independent experiments.

Northern blot analysis indicated that the amounts of PDS mRNA and PDS mRNA-derived siRNA in the systemically infected tissues were negatively correlated and were in accordance with the observed photobleaching phenotypes (Fig. 4B, iii). Significant amounts of $P D S$-homologous 21-nt siRNA were detected following infection with wtRNA1 + RNA2: PDS, which caused the most efficient PDS silencing (Fig. 4B, iii). These results were expected because 21-nt siRNA is produced by DCL4, which is the primary sensor of viral doublestranded RNA (dsRNA) (Xie et al. 2004). PDS-homologous 24-nt siRNA was detected following infection with all the different constructs and also in lower amounts in healthy $N$. benthamiana. Production of 24-nt siRNA by DCL3 depends on cellular RdRp 2 (RDR2) and controls transcriptional gene silencing (Kasschau et al. 2007; Matzke and Birchler 2005). The 24-nt siRNA constitutes the most abundant siRNA class in flowering plants, and its production from PDS mRNA might be associated with high expression levels of $P D S$.

\section{K stabilizes TRV RNA2:GFP.}

To augment noninvasive monitoring of systemic infection, green fluorescent protein (GFP) was inserted in TRV RNA2 (construct RNA2:GFP) (Fig. 1). N. benthamiana plants infiltrated with wtRNA1 + RNA2:GFP showed intensive GFP fluorescence in systemically infected leaves 9 dpi (Fig. 5A). In contrast, no GFP fluorescence was observed following infection with 16Kstop + RNA2:GFP or M1 + RNA2:GFP, although apparent symptoms of viral infection such as epinasty and necrosis, respectively, were observed in systemically infected leaves (Fig. 5A).

Northern blot analysis detected a band corresponding to the expected size of RNA2:GFP in leaves that were systemically infected with wtRNA1 + RNA2:GFP (Fig. 5B). In contrast, the leaves systemically infected with M1 + RNA2:GFP and 16Kstop + RNA2:GFP contained only truncated forms of RNA2:GFP at 9 dpi (Fig. 5B). Each type of infection was analyzed in three plants in three independent experiments and results were consistent. RT-PCR using RNA2-specific primers flanking GFP and sequencing of the PCR products revealed that the GFP insert was lost from the progeny viruses of $\mathrm{M} 1+$ RNA2:GFP. In addition, GFP and the RNA2 sequences flanking the GFP insert were lost from the progeny viruses of $16 \mathrm{Kstop}+$ RNA2:GFP in many plants (Fig. 5C). However, full-length RNA2:GFP was detected in the systemically infected leaves of all plants infected with wtRNA1 + RNA2:GFP, although some plants also had shorter PCR products, indicating recombination and deletion (Fig. 5C). Each type of infection was analyzed in six plants in three independent experiments and results were consistent, indicating that an absence of $16 \mathrm{~K}$ from RNA1 increased the instability of RNA2:GFP. On the other hand, the RNA1 mutants M1, M2, and 16Kstop were stable, as shown by analysis of the 3'-proximal part of RNA in the systemically infected leaves by RT-PCR followed by sequencing of the amplification products. 


\section{A}

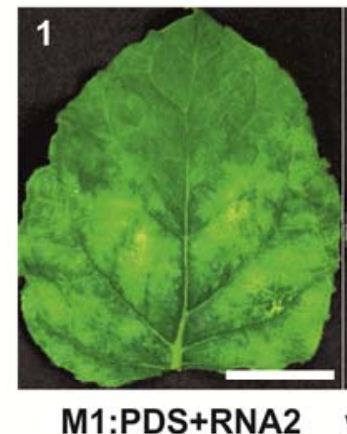

2

M1:PDS+RNA2

3

3

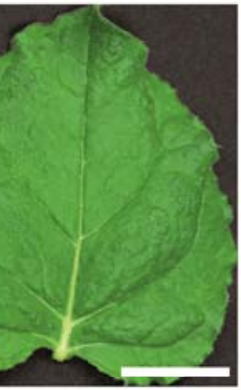

Control
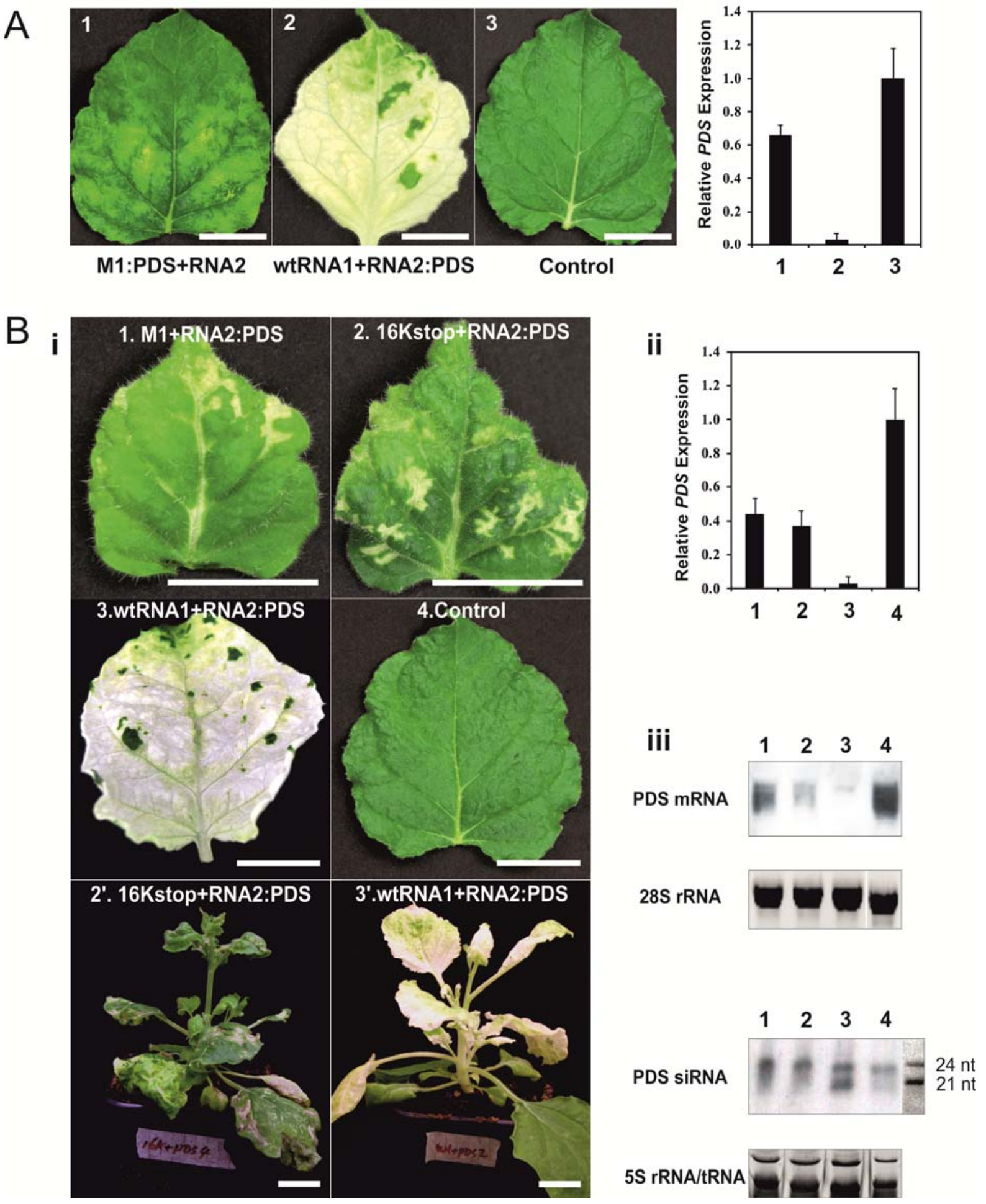

Fig. 4. Induction of phytoene desaturase (PDS) silencing (photobleaching) by Tobacco rattle virus (TRV) vectors in the systemically infected leaves of Nicotiana benthamiana. A, M1:PDS co-inoculated with RNA2 induced milder PDS silencing (chlorosis, leaf 1) than did co-inoculation with wild-type (wt)RNA1 and RNA2:PDS (leaf 2) at 20 days postinoculation (dpi). Control: uninoculated plant (leaf 3). Bars indicate $2 \mathrm{~cm}$. Samples taken from chlorotic and photobleached areas, respectively, after photography of leaves were subjected to quantitative reverse-transcription polymerase chain reaction (qRT-PCR) (right). Relative PDS mRNA expression in leaves systemically infected with (1) M1:PDS + RNA2 and (2) wtRNA1 + RNA2:PDS, and in (3) healthy plants. Error bars indicate standard error $(n=3)$. B, Panel i: at 15 dpi, M1 + RNA2:PDS (leaf 1) and 16Kstop + RNA2:PDS (leaf 2) induced less-intensive PDS silencing in the systemically infected leaves than did wtRNA1 + RNA2:PDS (leaf 3). Photos 2' and 3' show the whole plants at 20 dpi. Bars indicate $2 \mathrm{~cm}$. Panel ii: relative PDS mRNA expression levels analyzed by qRT-PCR in the leaves infected with TRV virus-induced gene silencing (VIGS) vectors at 15 dpi were correlated with the visual appearance of photobleaching. Numbers on the graph correspond to the leaves in panel i. Error bars indicate standard error $(n=3)$. Panel iii: Northern blot analysis on PDS mRNA and the corresponding 21- and 24-nucleotide (nt) small interfering (si)RNAs in photobleached areas of leaves infected with VIGS vectors at 15 dpi. Lane numbers correspond to the leaves in panel i. In the PDS siRNA blot, the rightmost lane shows 21- and 24nt siRNA markers run in the same gel. 28S and 5S ribosomal RNA (rRNA) and tRNA were used as loading controls in mRNA and siRNA analyses, respectively. 

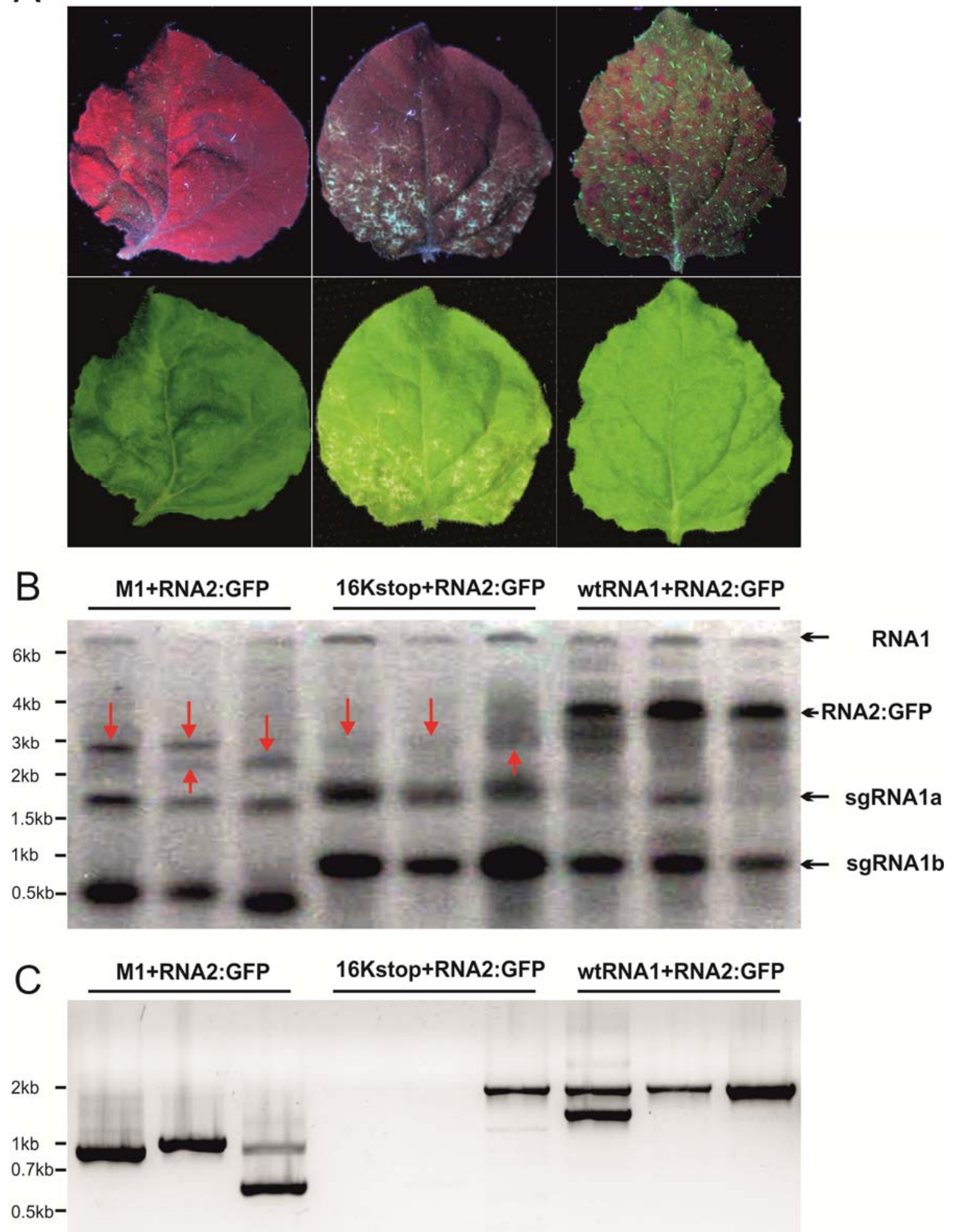

Fig. 5. Dysfunctional $16 \mathrm{~K}$ increases instability of RNA2:GFP during Tobacco rattle virus (TRV) infection in Nicotiana benthamiana. A, Green fluorescent protein (GFP) fluorescence in the systemically infected leaves at 9 days postinoculation (dpi). Photos in the upper panel were taken under UV light to reveal GFP fluorescence, whereas photos in the lower panel were taken under normal light. Necrotic tissue in the leaf infected with 16Kstop + RNA2:GFP shows autofluorescence under UV light. B, Northern blot analysis using 3' untranslated region as a probe revealed only truncated forms of RNA2:GFP (arrows) at 9 dpi in the systemically infected leaves of plants inoculated with M1 + RNA2:GFP and 16Kstop + RNA2:GFP. Shorter sizes of subgenomic (sg)RNA1a and sgRNA1b in M1 are due to the introduced deletion in the $16 \mathrm{~K}$ gene. C, Reverse-transcription polymerase chain reaction (RT-PCR) analysis with primers flanking the GFP insert revealed the PCR product of expected size (approximately $2 \mathrm{~kb}$ ) in the leaves systemically infected with wtRNA1 + RNA2:GFP. In contrast, truncated forms of RNA2 lacking GFP (M1 + RNA2:GFP) or, usually, no amplification products (16Kstop + RNA2:GFP) indicating the frequent loss of RNA2 regions that flank GFP, were detected following systemic infection with the RNA1 mutants carrying a dysfunctional $16 K$ gene. Three lanes per construct represent samples from three different plants. 
TMV 30K can substitute for TRV $29 \mathrm{~K}$ as an MP in TRV.

TRV mutants that were unable to express $16 \mathrm{~K}$ unexpectedly induced more-severe necrotic symptoms than did the wtRNA1. Because the 29K MP of TRV induces necrotic symptoms in plants (Ghazala and Varrelmann 2007; Ziegler-Graff et al. 1991) and the 30K MP of TMV can functionally complement defective 29K of TRV in trans (Ziegler-Graff et al. 1991), two additional TRV RNA1 mutants were developed by replacing $29 K$ with TMV $30 K$ in wtRNA1 (construct trv30K) and 16Kstop (trv30K16Kstop) (Fig. 1).

Agroinfiltration of trv30K (without RNA2) into leaves of $N$. benthamiana induced necrosis first in the infiltrated leaf and, subsequently, in the petiole and the base of the stem (Fig. 6A). The expanding apical leaves displayed necrosis in petioles and leaf veins by $16 \mathrm{dpi}$. This pattern of symptom development in the trv30K-infected plants was consistent with systemic spread of TMV-GFP in $N$. benthamiana (Kreuze et al. 2005). Top necrosis was observed in a few systemically infected plants (Fig. 6B), and all plants were stunted (Fig. 6D). In contrast, agroinfiltration with trv30K16Kstop (without RNA2) caused necrosis only in infiltrated leaves and petioles (Fig. 6C). No spread of symptoms and virus beyond the base of the petiole was observed by 21 dpi (Fig. 6D) and 30 dpi at termination of the experiment, indicating that the virus was unable to pass through the abscission zone (Vuorinen et al. 2011).

Analysis of the inoculated leaves by Northern blot hybridization revealed sgRNA1a and sgRNA1b for trv30K16Kstop and trv30K, which indicated that both viruses were able to replicate, although the RNAs of trv30K16Kstop accumulated at very low titers and were detected only following extended exposure time (Supplementary Fig. S3A). Furthermore, the RNA titers of both of these viruses were lower than those of wtRNA1, $16 \mathrm{Kstop}$, and M1.

Inoculation with trv30K + RNA2 and trv30K16Kstop + RNA2 induced milder symptoms than did infection with trv30K and trv30K16Kstop alone. Leaves systemically infected with trv30K + RNA2 displayed mosaic symptoms and mild epinasty (Fig. 6E), similar to the symptoms described for TMV (Shew and Lucas 1991), and the symptoms appeared 3 to 5 days earlier than after infection with trv30K alone. RT-PCR results showed that RNA1 was present in the apical leaves of plants infected with trv30K + RNA2 but was absent from plants inoculated with trv30K16Kstop either alone or with RNA2.

Co-infiltration of trv30K with RNA2:PDS or RNA2:GFP caused photobleaching (Fig. 6J) or the appearance of GFP fluorescence (Fig. 6G), respectively, in the apical noninoculated $N$. benthamiana leaves at $25 \mathrm{dpi}$, which was not observed with trv30K16Kstop + RNA2:GFP (Fig. 6H). In plants co-

Fig. 6. Systemic infection and symptoms induced with Tobacco rattle virus (TRV) RNA1 mutants trv30K and trv30K16Kstop in Nicotiana benthamiana. All photos were taken 21 days postinoculation (dpi) unless specified differently. A, Severe necrosis in the petiole of the leaf inoculated with trv $30 \mathrm{~K}$ and in the base of the stem. B, Apical necrosis caused by trv30K at 28 dpi. C, Severe necrosis in the petiole of a leaf inoculated with trv30K16Kstop. Necrosis did not expand to the stem base. D, Severe stunting of a plant systemically infected with trv30K (left) as compared with a plant inoculated with trv30K16Kstop (right), which shows no systemic symptoms. E, Vein clearing and epinasty in a leaf systemically infected with trv30K + RNA2. F, Leaf systemically infected with wtRNA1 + RNA2. G, Green fluorescent protein (GFP) fluorescence in the systemically infected leaves of plants infected with trv30K + RNA2:GFP. H, No GFP fluorescence was observed in the apical noninoculated leaves of plants inoculated with trv30K16Kstop + RNA2:GFP. I, GFP fluorescence in a plant infected with wtRNA1 + RNA2:GFP. J, Phytoene desaturase (PDS) silencing induced by trv30K + RNA2:PDS at 25 dpi. Bars in E and $\mathrm{F}=1 \mathrm{~cm}$; in other panels, $\mathrm{bar}=2 \mathrm{~cm}$. infiltrated with wtRNA1 + RNA2:GFP, the systemically infected leaves expressed GFP fluorescence by 21 dpi (Fig. 6I).

Similar results were found for three independent experiments. Taken together, they showed that TMV 30K MP was able to substitute for TRV $29 \mathrm{~K}$ as an MP in cis and altered, but did not alleviate, virus symptoms. However, accumulation of TRV was reduced and systemic movement was delayed after substitution of $29 K$ with TMV $30 K$.

\section{TRV 29K contributes to suppression of RNA silencing.}

The ability of TRV 29K, TRV 16K, and TMV 30K to interfere with sense-mediated RNA silencing (co-suppression) was tested using the "silencing on the spot" agroinfiltration assay (Johansen and Carrington 2001) in leaves of GFP-transgenic $N$. benthamiana line 16c (Brigneti et al. 1998). TRV 29K and TMV $30 \mathrm{~K}$ were unable to prevent GFP silencing when expressed in the leaves by agroinfiltration together with a binary
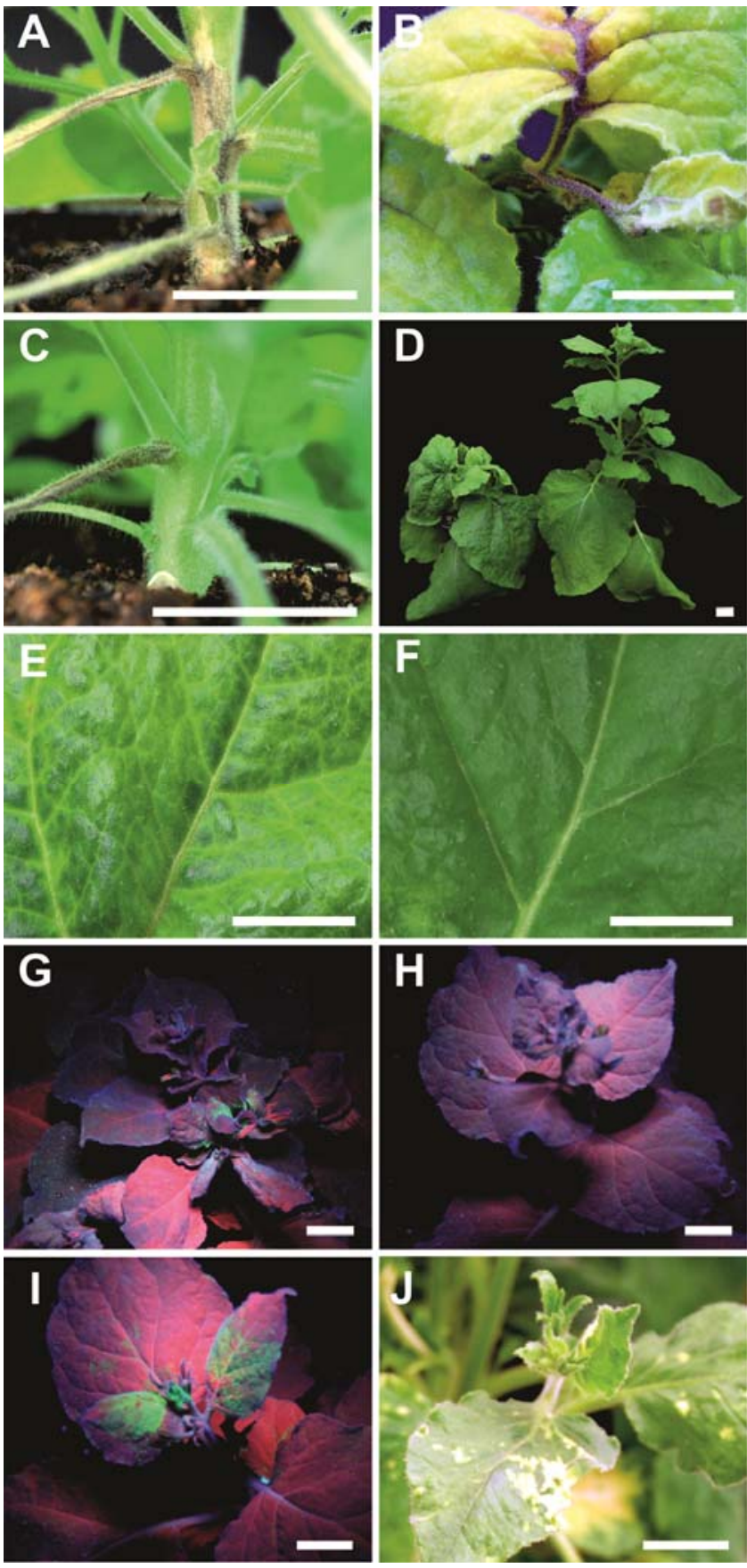
vector expressing GFP mRNA to induce GFP co-suppression (Supplementary Fig. S4). In contrast, co-infiltration of GFP and the binary vector for expression of TRV 16K (MartínezPriego et al. 2008) or HC-Pro of Potato virus A (Kreuze et al. 2005; Rajamäki and Valkonen 2009) prevented GFP silencing and supported strong expression of GFP fluorescence.

Subsequently, the infectious RNA1 mutants and wtRNA1 were tested for their ability to interfere with GFP silencing. As expected, GFP fluorescence initially increased in the agroinfiltrated tissue up to 2 to 3 dpi because of GFP overexpression from the introduced binary vector but subsequently diminished by 5 dpi because of co-suppression in leaf tissues lacking an agroinfiltration-introduced silencing suppressor (Fig. 7A, right side of the leaves). wtRNA1 was most efficient in silencing suppression. In addition, M1, M2, 16Kstop, and trv30K showed relatively efficient and similar suppression of $G F P$ silencing, in contrast to trv30K16Kstop, which did not prevent GFP silencing (Fig. 7A, left side of the leaves). GFP fluorescence from 3 to 7 dpi was positively correlated with GFP mRNA levels and negatively correlated with accumulation of GFP-derived siRNAs in the agroinfiltrated leaf tissue (Fig. 7C). Differences in silencing suppression were further highlighted in the leaves systemically infected with RNA1. wtRNA1, and all other RNA1 constructs carrying $29 K$ (M1, M2, and 16Kstop) enhanced GFP fluorescence regardless of whether they contained $16 K$, and trv $30 \mathrm{~K}$ enhanced GFP fluorescence despite the lack of $29 K$ (Fig. 7B).

Taken together, these data show that all RNA1 mutants devoid of TRV $16 K$ (M1, M2, and 16Kstop) or $29 K$ (trv30K) but not both genes (trv30K16Kstop) could suppress sense-mediated silencing and that silencing suppression by $29 \mathrm{~K}$ was associated with multiplication of RNA1.

\section{DISCUSSION}

This study aimed to develop a VIGS vector based on TRV RNA1 by partial removal of $16 \mathrm{~K}$ to vacate space for the heter-
A

M1

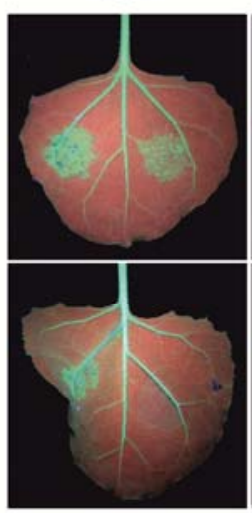

M1

B

$14 \mathrm{dpi}$

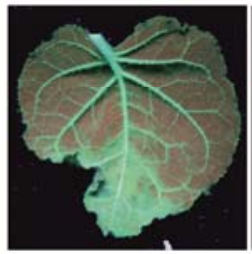

M2

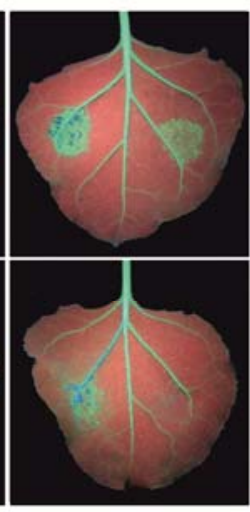

M2

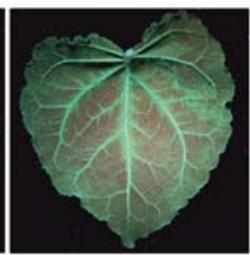

16Kstop

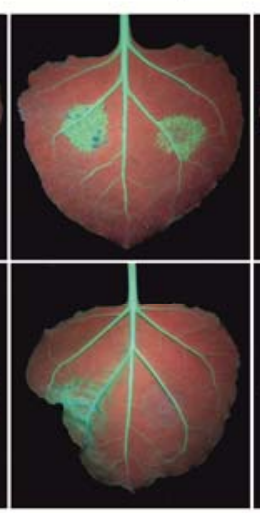

16Kstop

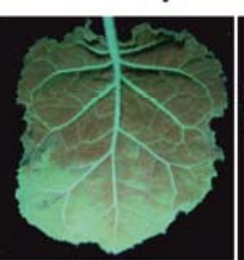

wtRNA1

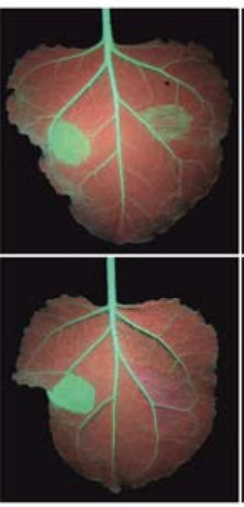

wtRNA1

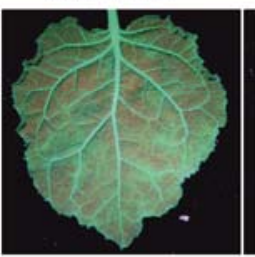

trv30K

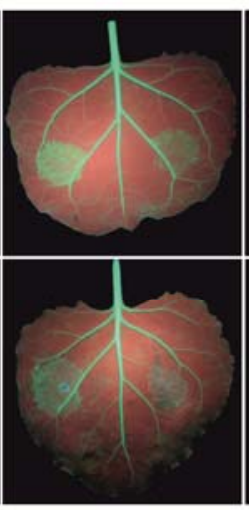

$\operatorname{trv} 30 \mathrm{~K}$

trv30K16Kstop

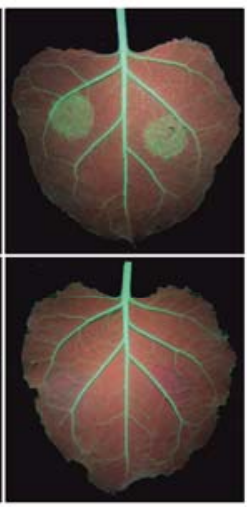

trv30K16Kstop

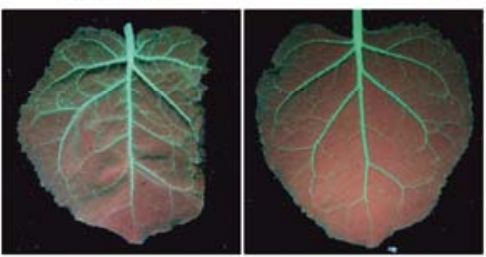

C

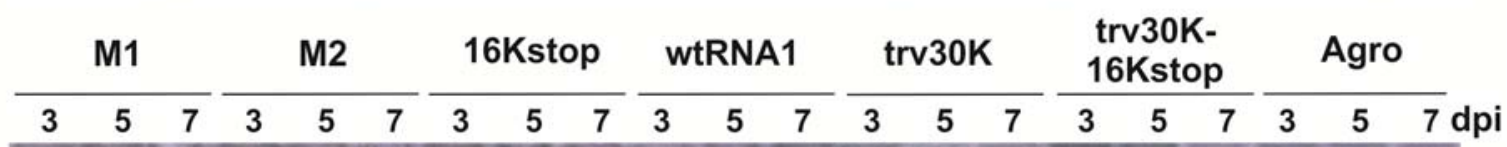

GFP mRNA

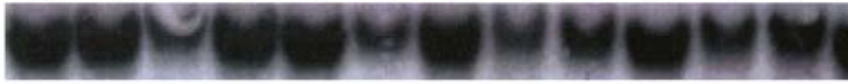

28S rRNA

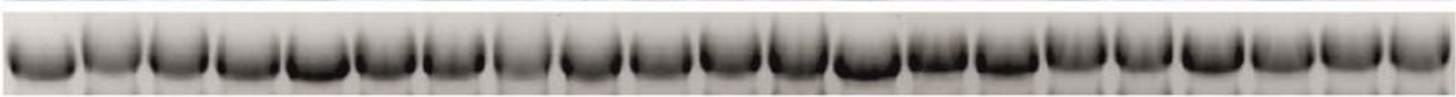

\section{1-24 siRNA}

5S rRNA/tRNA
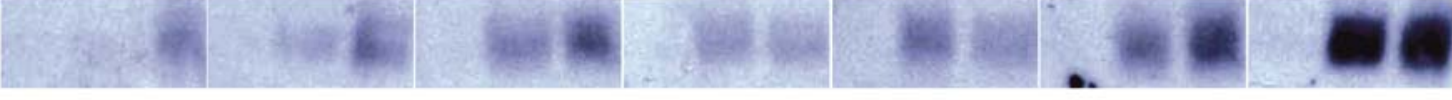

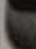

Fig. 7. Suppression of sense-mediated silencing of green fluorescent protein (GFP) expression by Tobacco rattle virus (TRV) RNA1 and its mutated forms. A, Induction of GFP silencing in leaves of the GFP-transgenic Nicotiana benthamiana line 16c by overexpression of GFP mRNA "on the spot" from an introduced binary vector pBIN:GFP by agroinfiltration (right and left side of the leaves) and interference with silencing by introducing TRV wild-type (wt)RNA1 or RNA1 mutants by co-infiltration with pBIN:GFP (left side only of the leaves). Suppression of silencing was indicated by GFP fluorescence in the co-infiltrated leaf tissue 5 days postinoculation (dpi). B, Effect of systemic infection with TRV wtRNA1 and mutants on the expression level of GFP fluorescence in the systemically infected leaves of the 16c plants at 14 dpi. C, Northern blot analysis for detection of GFP mRNA and small interfering (si)RNA in tissues co-infiltrated with pBIN:GFP and the RNA1 construct at 3, 5, and 7 dpi. GFP was used as a probe. 'Agro' indicates infiltration with Agrobacterium carrying a binary vector without an insert (control); 21-24 siRNA represents the 21- and 24-nucleotide siRNAs. 28S and 5S ribosomal RNA (rRNA) and transfer RNA were used as loading controls. 
ologous insert and to reduce the silencing suppression capacity of TRV. The M1 and M2 vectors were infectious and competently spread systemically without $16 \mathrm{~K}$, in accordance with two previous studies (Guilford et al. 1991; Martín-Hernández and Baulcombe 2008), and could be used to induce partial silencing of PDS in systemically infected leaves of $N$. benthamiana. However, systemic spread of M1 and M2 was delayed as compared with wtRNA1, and silencing achieved with M1:PDS was not as efficient as with M1 + RNA2:PDS or wtRNA1 + RNA2:PDS. One reason may be that, because TRV RNA1 encodes the proteins needed for replication of RNA1 and RNA2, targeting RNA1 rather than RNA2 to silencing probably reduces the capacity to produce silencing-inducing PDS RNA as compared with when silencing is primarily targeted to RNA2, as in the commonly used TRV-based VIGS vectors (Liu et al. 2002b; Ratcliff et al. 2001). The impaired ability to suppress silencing also impaired invasiveness and accumulation of RNA1 mutants in plant tissues. The balance of silencing and silencing suppression for efficient VIGS seems to be more optimal with wtRNA1 than any of the RNA1 mutants.

Studies on mutant trv30K showed that TMV 30K MP, when used in cis to replace TRV $29 \mathrm{~K}$ in TRV RNA1, maintained cell-to-cell and long-distance movement functions for TRV RNA1 and RNA2, which is supported by a previous study showing that $30 \mathrm{~K}$ can complement movement of $29 \mathrm{~K}$-defective TRV mutants in trans (Ziegler-Graff et al. 1991). However, when expression of $16 \mathrm{~K}$ was interrupted in the recombinant RNA1 carrying TMV 30K (mutant trv30K16Kstop), virus accumulation was greatly reduced in inoculated leaves, and no systemic infection was observed. Synthesis of sgRNAs provided evidence that trv30K16Kstop was able to replicate in the agroinoculated leaf tissue, but accumulation of viral RNAs remained at a very low level. These results suggest that trv30K16Kstop could not suppress RNA silencing, in contrast to the viral mutants encoding $16 \mathrm{~K}$ or $29 \mathrm{~K}$, which accumulated to high titers, albeit not to titers as high as wtRNA1, which encodes both $16 \mathrm{~K}$ and $29 \mathrm{~K}$. These data, together with the results from silencing-suppression experiments, indicate that TRV $29 \mathrm{~K}$ contributes to suppression of RNA silencing, which has previously been reported only for 16K of TRV (Ghazala et al. 2008; Martín-Hernández and Baulcombe 2008; MartínezPriego et al. 2008; Reavy et al. 2004). Because the key experiments on silencing suppression were done using only RNA1, any contribution of RNA2 or CP to silencing suppression observed in this study could be excluded.

The $16 \mathrm{~K}$ protein suppresses silencing when expressed alone, as shown by our study and previous reports (Ghazala et al. 2008; Martín-Hernández and Baulcombe 2008; Martínez-Priego et al. 2008). In contrast, RNA silencing suppression by $29 \mathrm{~K}$ was revealed only in the context of RNA1 replication. Hence, $29 \mathrm{~K}$ seems to protect viral RNA from silencing in an intimate association with the replication complex but does not require $16 \mathrm{~K}$ for this activity (mutants M1, M2, and 16Kstop). On the other hand, 194K, which is encoded by RNA1 and encompasses the viral replicase, helicase, and methyl transferase functions, was not able to suppress silencing in the absence of $29 \mathrm{~K}$ (mutant trv30K16Kstop). These results indicate that, whereas $16 \mathrm{~K}$ suppresses RNA silencing independently, silencing suppression by $29 \mathrm{~K}$ and $194 \mathrm{~K}$ are interdependent.

The $29 \mathrm{~K}$ protein is associated with TRV-induced symptoms (Ghazala and Varrelmann 2007; Ziegler-Graff et al. 1991), and overexpression of $29 \mathrm{~K}$ under the control of the CaMV $35 \mathrm{~S}$ promoter induces necrosis in potato cultivars (Ghazala and Varrelmann 2007). The RNA1 mutants carrying a dysfunctional $16 \mathrm{~K}$ (M1, M2, and 16Kstop) or in which $29 \mathrm{~K}$ was substituted with TMV $30 K$ (mutant trv30K) caused necrotic symptoms in the inoculated and systemically infected leaves of
$N$. benthamiana, consistent with results obtained using another TRV RNA1 mutant in which the expression of $16 \mathrm{~K}$ was prevented (Martín-Hernández and Baulcombe 2008). Hence, $29 K$ and $16 \mathrm{~K}$ of TRV appear to have coordinated functions during the infection cycle of TRV, which alleviate host responses that are deleterious to the virus and which are also important for successful use of TRV as a VIGS vector. The TMV $30 \mathrm{~K}$ MP gene was not competent to substitute for TRV $29 \mathrm{~K}$ in this respect, as indicated by the severe necrotic symptoms caused by trv30K that carried $16 \mathrm{~K}$. Necrotic symptoms are also induced following overexpression of 29K (Ziegler-Graff et al. 1991) or $16 \mathrm{~K}(\mathrm{H}$. Liu et al. 2002a) from an additional copy of the gene cloned in place of the $16 \mathrm{~K}$ ORF in RNA1 or into RNA2, respectively, further supporting the requirement of balanced production of $16 \mathrm{~K}$ and $29 \mathrm{~K}$ to maintain favorable conditions for the infection cycle of TRV.

It was unexpected to find the most severe necrotic symptoms in $N$. benthamiana induced by the mutant 16 Kstop that contains only a few nucleotide substitutions in the beginning of the $16 \mathrm{~K}$ ORF that prevent $16 \mathrm{~K}$ expression. According to MacFarlane (2010), the ORF for $16 \mathrm{~K}$ contains another, putative ORF for a $13 \mathrm{~K}$ protein in a different reading frame but little is known about whether the putative $13 \mathrm{~K}$ protein is produced during the infection cycle of TRV. The $13 \mathrm{~K}$ ORF would remain unaffected in 16Kstop, unlike the mutants M1 and M2 lacking most of the 16K ORF. Overlapping ORF are common in RNA viruses (Chirico et al. 2010; Chung et al. 2008; McFadden et al. 2011), and the proteins expressed from overlapping ORF typically play a role in viral pathogenicity and spread (McFadden et al. 2011; Rancurel et al. 2009). At present, the existence of $13 \mathrm{~K}$ and its role in the severe necrosis induced by $16 \mathrm{Kstop}$ remain enigmatic.

Coordinated functions of RNA1 and RNA2 were evident in the experiments using the RNA1 mutants. In the absence of a functional $16 \mathrm{~K}$ (mutants M1, M2, and 16Kstop), necrotic symptoms were induced in $N$. benthamiana infected with TRV RNA1. Co-infection with wtRNA2 (or RNA2:PDS) did not alleviate necrosis but enhanced systemic infection. Infection with trv30K also caused severe necrosis in inoculated leaves as well as necrosis in apical leaves following systemic infection but these severe necrotic symptoms were not observed in the leaves systemically infected with trv30K + RNA2:GFP or trv30K + RNA2:PDS. Therefore, whereas TMV $30 \mathrm{~K}$ was not able to complement the silencing-suppression functions of $29 \mathrm{~K}$ in TRV infection, it could complement the putative functions of $29 \mathrm{~K}$ that are needed to inhibit the harmful host responses and that involve RNA2, the CP encoded by RNA2, or both. This model gains support from previous studies on transgenic tobacco plants that express the TMV $30 \mathrm{~K}$ and do not develop necrotic symptoms following infection with a TRV $29 \mathrm{~K}$ mutant that causes necrosis in wild-type tobacco plants (Ziegler-Graff et al. 1991).

The coordinated functions of RNA1 and RNA2 were also evident with the increased instability of the GFP insertion in RNA2 in infections involving RNA1 that carried a dysfunctional form of $16 \mathrm{~K}$. This result is potentially significant because it suggests that the silencing suppression may be functionally linked to suppression of recombination during virus replication. Variability in size and gene content of RNA2 is characteristic of isolates of TRV and other tobraviruses, including recombination of $3^{\prime}$ proximal sequences from RNA1 to RNA2 (MacFarlane 2010), and the role of $16 \mathrm{~K}$ (or the putative $13 \mathrm{~K}$ ) might be to control these events. The $16 \mathrm{~K}$ protein is believed to interfere with RNA silencing after the initial step of recognition and cleavage of long dsRNA molecules by DCL (Martínez-Priego et al. 2008). Next, siRNA molecules bind to and guide the RNA silencing complex containing an ssRNA-specific ribonuclease (AGO1 or AGO2) to cleave and inactivate the homologous ssRNA mole- 
cules (Harvey et al. 2011). A secondary pool of virus-derived siRNA is generated by the cellular RdRps RDR1 and RDR6, which recognize cleaved ends of ssRNA and synthesize a complementary strand, hence producing new substrates for DCL (Qu 2010). Whether i) the viral ssRNA cut by AGO can be used as a template by the viral RdRps and ii) there is competition for viral ssRNA by the viral and host RdRps need to be determined in the context of template switching reported for RdRps of many viruses (Sztuba-Solinska et al. 2011). Such potential competition may explain the acceleration of recombination in the absence of $16 \mathrm{~K}$, which might suppress recombination by interfering with AGO and the cleavage of viral RNAs. Many unrelated viral silencing suppressors interfere with AGOs or host RdRps (Baumberger et al. 2007; Bortolamiol et al. 2007; Du et al. 2011; Glick et al. 2008). Nuclear localization (Liu et al. 1991) may also have a role in the putative mechanism of silencing suppression of 16K (Ghazala et al. 2008). The silencing-suppressor proteins of a few other plant-infecting RNA viruses accumulate in the nucleus and nucleolus (Rajamäki and Valkonen 2009; Taliansky et al. 2010). According to some studies, the $2 \mathrm{~b}$ protein of Cucumber mosaic virus interacts with AGOs in the nucleolus to facilitate silencing suppression functions (Duan et al. 2012), whereas other studies suggest that nuclear localization of the $2 b$ protein is not required for silencing suppression (Gonzalez et al. 2012 ). Many questions related to control of recombination by the $16 \mathrm{~K}$ ORF remain to be addressed in future studies, but the findings reported here provide another perspective of the factors playing a role in stability of heterologous gene insertion in viral genomes and VIGS vectors.

Taken together, this study showed that it is possible, with some limitations, to use RNA1 of TRV as a VIGS vector in $N$. benthamiana, in addition to its previous use as a vector for expression of heterologous proteins such as TMV CP (Guilford et al. 1991) or an extra copy of TRV 29K (Ziegler-Graff et al. 1991) in tobacco leaves. Results also suggested coordinated functions between $29 \mathrm{~K}$ and $16 \mathrm{~K}$, and TRV RNA1 and RNA2, which alleviate host responses harmful to the virus. Most importantly, suppression of RNA silencing by $29 \mathrm{~K}$ was detected and found to work only in association with viral replication, which was different from $16 \mathrm{~K}$ that also suppressed silencing independently. These findings provide new insights into silencing suppression by TRV and suggest different mechanisms used by $29 \mathrm{~K}$ and $16 \mathrm{~K}$. Altogether, the results shed new light on virulence factors of TRV.

\section{MATERIALS AND METHODS}

\section{Plasmid constructs.}

The binary vectors pBINTRA6 and pTV00 containing the cDNA of TRV RNA1 and RNA2, respectively, under the CaMV 35S promoter have been described (Ratcliff et al. 2001) and were obtained from the Sainsbury Laboratory, Norwich, U.K. (courtesy of D. C. Baulcombe). pTV00 contained a multiple cloning site. Details of these binary vectors and the five TRV RNA1 mutants made in this study are provided in Figure 1. The primers used for mutagenesis, cloning, and PCR are listed in Supplementary Table S1.

An intermediate plasmid, pJK1, was constructed by digesting pBINTR6 with SalI and SmaI and introducing the digested fragment (nucleotides 3,786 to 7,653; GenBank accession number AX391686) into the pBluescript II SK(+/) plasmid (Fermentas, St. Leon Rot, Germany). This fragment of TRV RNA1 contains the $29 K$ and $16 K$ genes and part of the $R d R p$ gene and was the target of mutations introduced using the SiteDirected Mutagenesis Kit (Finnzymes, Espoo, Finland). Subsequently, mutated viral genome fragments were digested and introduced back into pBINTRA6 using SalI and SmaI sites.
For mutant M1, the $3^{\prime}$-proximal deletion and a stop codon were introduced simultaneously into $16 \mathrm{~K}$ using PCR (primers $16 \mathrm{~K} \_\mathrm{dM} 1 \mathrm{~F}$ and $\left.16 \mathrm{~K} \_\mathrm{dM} 1 \mathrm{R}\right)$. For mutant $16 \mathrm{Kstop}$, one premature stop codon was introduced by PCR (primers 16K_StopF and $16 \mathrm{~K} \_$StopR), and the fourth codon of $16 \mathrm{~K}$ was mutated from GTA to TGA. Mutant M2 was generated from 16Kstop by PCR with primers $16 \mathrm{~K} \_\mathrm{dM} 2 \mathrm{~F}$ and $16 \mathrm{~K} \_\mathrm{dM} 2 \mathrm{R}$. Two restriction sites, PacI and AscI, were introduced into M1 and M2 by PCR. Mutants 16Kstop and M1 were similar to those used by Guilford and associates (1991).

To construct trv $30 \mathrm{~K}$, the whole $29 \mathrm{~K}$ gene was first removed from the intermediate plasmid pJK1 (primers 29K_dF and 29K_dR) and replaced with TMV $30 K$ that had been amplified by PCR (primers trv30K_F and trv30K_R) from the plasmid TMV p30B-GFPC3 (courtesy of W. O. Dawson, Citrus Research and Education Center, Florida) (Kreuze et al. 2005; Shivprasad et al. 1999). Mutant trv30K16Kstop was generated from trv30K essentially as described for 16Kstop.

A fragment of PDS from $N$. benthamiana (GenBank accession number EU165355.1) corresponding to nucleotides 1,094 to 1,295 was amplified by PCR (primers PDS_F and PDS_R) and cloned into M1 and M2 using AscI, resulting in constructs M1:PDS and M2:PDS, respectively. RNA2:PDS was constructed by cloning the same PDS fragment into pTV00.

RNA2:GFP was designed as described (MacFarlane and Popovich 2000). The complete GFP gene was amplified by PCR from Potato virus A (PVA):GFPuv (primers GFPuv_F and Gateway_GFP_R) (Rajamäki et al. 2005). The CP promoter (subgenomic RNA promoter [sgP], $237 \mathrm{nt}$ ) of Pea earlybrowning virus (MacFarlane and Popovich 2000) was constructed from synthesized oligonucleotides by PCR. sgP and GFP sequences were fused and cloned to the gateway plasmid pYL179 (provided by S. P. Dinesh-Kumar, University of California, Davis) (Liu et al. 2002c) according to the manufacturer's instructions to obtain RNA2:GFP.

The binary vectors pBIN:GFP (Haseloff et al. 1997; Voinnet et al. 1998) and pA:HcPro (Savenkov and Valkonen 2001) have been described. pA:16K, pA:29K, and pA:30K were developed based on pA:HcPro by replacing the PVA HC-Pro sequence for PCR-amplified $16 K, 29 K$, and $30 K$, respectively (primers 16K_F and 16K_R, 29K_F and 29K_R, and 30K_F and 30K_R, respectively).

\section{Plant material.}

Seed of the GFP-transgenic $N$. benthamiana line $16 \mathrm{c}$ (Brigneti et al. 1998) (supplied by D. Baulcombe) and wildtype $N$. benthamiana seed were planted in soil prepared by mixing peat (Kekkilä Horticulture Peat, Kekkilä Oyj, Finland) and washed sand at a 5:1 ratio (vol/vol). Plants were grown in a growth room under controlled conditions $\left(21\right.$ and $19^{\circ} \mathrm{C}$ day and night temperatures, respectively; 16 -h photoperiod; 250 $\mu \mathrm{mol} \mathrm{m} \mathrm{m}^{-2} \mathrm{~s}^{-1}$ light intensity; and $40 \%$ relative humidity). The plants were watered when needed and fertilized weekly with a $1.0 \%$ solution of $\mathrm{N} / \mathrm{P} / \mathrm{K}(8: 4: 6$ or $16: 9: 22)$ fertilizer (Yara, Espoo, Finland).

\section{Virus infection and agroinfiltration.}

Binary vectors were introduced into Agrobacterium tumefaciens C58Ci(pGV2260) (Deblaere et al. 1985). Agrobacterium cells were grown and collected as described (Liu et al. 2002c) and resuspended in infiltration medium containing 10 mM 2-( $N$-morpholino) ethanesulfonic acid, $200 \mu \mathrm{M}$ acetosyringone, and $10 \mathrm{mM} \mathrm{MgCl}_{2}$. For virus inoculations, the Agrobacterium suspension was diluted to an optical density at 600 $\mathrm{nm}\left(\mathrm{OD}_{600}\right)=1$ and, for silencing suppression assays, to $\mathrm{OD}_{600}=$ 0.4. The diluted Agrobacterium suspensions were incubated at room temperature for $3 \mathrm{~h}$. For co-infiltration with two plasmids, 
the two respective Agrobacterium cultures were mixed 1:1 ( $\mathrm{vol} / \mathrm{vol})$ before infiltration. Agrobacteria were syringe infiltrated into the lower side of leaves using 1-ml syringes lacking a needle. For virus infection and VIGS, 4-week-old seedlings were agroinfiltrated at the four-leaf stage. For the transient Agrobacterium-mediated expression assay, approximately 6-weekold plants were agroinfiltrated at the eight-leaf stage.

\section{Northern blot analysis.}

Total RNA was extracted with TRIzol Reagent (Invitrogen, Carlsbad, CA, U.S.A.). Low molecular weight (LMW) and high molecular weight (HMW) RNAs were separated in the presence of $2 \mathrm{M}$ lithium chloride as described (Llave et al. 2000) and used for siRNA and mRNA detection, respectively. For mRNA analysis, $10 \mu \mathrm{g}$ of HMW RNA was separated on a $1.2 \%$ (wt/vol) formaldehyde agarose gel by electrophoresis, transferred to a nylon membrane (Hybond-N; Amersham, Bucks, U.K.), and crosslinked with UV light. To analyze siRNA, $15 \mu \mathrm{g}$ of LMW RNA was mixed with an equal volume of deionized formamide and separated by electrophoresis in a denaturing polyacrylamide gel $(15 \%, \mathrm{wt} / \mathrm{vol})$. RNA was transferred to a nylon membrane (Hybond NX; Amersham) and cross-linked with EDC cross-linking solution (Pall and Hamilton 2008). Prehybridization, hybridization, and washing were done as described (Hamilton and Baulcombe 1999). A DNA probe labeled with Dig-11-dUTP (Roche, Mannheim, Germany) corresponding to the 3' untranslated region of TRV RNA1 was PCR amplified and used to detect TRV RNA2, TRV RNA1, and the sgRNAs (Fig. 1). For detection of mRNA and siRNA of $P D S$ and $G F P$, antisense PDS and GFP RNA probes were synthesized and randomly labeled with $\left[\alpha-{ }^{32} \mathrm{P}\right] \mathrm{rUTP}$ (Perkin Elmer, Boston) through in vitro transcription (T3 RNA polymerase; Promega, Charbonnières, France) using the following templates: ApaI-digested pGEM-T (Promega Corp., Madison, WI, U.S.A.) carrying an 801-nt fragment of $N$. benthamiana PDS, or XbaI-digested pGFPuv (GenBank accession number U62636) carrying the full-length GFP ORF (717 nt) (Kreuze et al. 2005). For hybridization with siRNAs, the probe was cleaved by alkaline hydrolysis to approximately 50-nt fragments, as described (Hamilton and Baulcombe 1999). After final washing, the blots were wrapped in polyethylene plastic and exposed to film (Kodak, Rochester, NY, U.S.A.).

\section{qRT-PCR.}

First-strand cDNA was synthesized from $1 \mu \mathrm{g}$ of total RNA using SuperScript III Reverse Transcriptase Kit (Invitrogen). cDNA $(20 \mu \mathrm{l})$ was diluted 10 -fold to a final volume of $200 \mu \mathrm{l}$. qPCR was performed using the LightCycler 480 Real-Time PCR System (Roche). The PCR master mix (15 $\mu \mathrm{l})$ contained $4.5 \mu \mathrm{l}$ of cDNA, $7.5 \mu \mathrm{l}$ of LightCycler 480 SYBR Green I Master mix, and $1.5 \mu \mathrm{l}$ of $(5 \mu \mathrm{M})$ each primer. The thermal cycler program was an initial cycle of denaturation $\left(95^{\circ} \mathrm{C}\right.$ for 10 min) followed by 45 cycles of amplification $\left(95^{\circ} \mathrm{C}\right.$ for $10 \mathrm{~s}$, $62^{\circ} \mathrm{C}$ for $10 \mathrm{~s}$, and $72^{\circ} \mathrm{C}$ for $10 \mathrm{~s}$ ). The $N$. benthamiana elongation factor $1 \alpha(E F 1 \alpha)$ gene (GenBank accession number AY206004.1) was used as an internal control for normalization of data (primers qPCR_EF1a_F and qPCR_EF1a_R). qPCR efficiencies were calculated with the LightCycler 480 program by analyzing a dilution series of cDNA. The relative expression ratios of each mRNA were calculated as described (Pfaffl 2001), with normalization based on $E F 1 \alpha$.

\section{GFP imaging.}

GFP fluorescence was monitored with a hand-held UV source (Black-Ray, Upland, CA, U.S.A.). Images were captured with a digital camera (Canon EOS 40D; Canon, Tokyo) equipped with a Canon EFS 17- to 85-mm objective lens. The images were further analyzed with the CorelDRAW X5 program (Corel Corp., Ottawa, ON, Canada).

\section{ACKNOWLEDGMENTS}

We thank M. L. Rajamäki and Y. Tian at our department for their kind help and valuable discussions and D. C. Baulcombe (University of Cambridge, U.K.), S. P. Dinesh-Kumar (University of California, Davis), and W. O. Dawson (University of Florida) for providing important materials. This study was financially supported by the Academy of Finland (grants 1118766,1134759 , and 1253126 to J. P. T. Valkonen; 139092 to P. Elomaa; and 139513 to T. H. Teeri), The Finnish Doctoral Program in Plant Sciences (to X. Deng and T. Haikonen), The Helsinki Graduate Program in Biotechnology and Molecular Biology (to A. L. Vuorinen), and The Viikki Doctoral Program in Molecular Biosciences (to J. Kelloniemi).

\section{LITERATURE CITED}

Adams, M. J., Heinze, C., Jackson, A. O., Kreuze, J. F., MacFarlane, S. A., and Torrance, L. 2012. Genus Tobravirus. Pages 1156-1159 in: Virus Taxonomy: Classification and Nomenclature of Viruses. The Ninth Report of the International Committee on Taxonomy of Viruses. M. Q. K. Andrew, L. Elliot, J. A. Michael, and E. B. Carstens, eds. Elsevier, San Diego, CA, U.S.A.

Baumberger, N., Tsai, C. H., Lie, M., Havecker, E., and Baulcombe, D. C. 2007. The polerovirus silencing suppressor P0 targets Argonaute proteins for degradation. Curr. Biol. 17:1609-1614.

Bortolamiol, D., Pazhouhandeh, M., Marrocco K., Genschik, P., and ZieglerGraff, V. 2007. The polerovirus F Box protein P0 targets ARGONAUTE1 to suppress RNA silencing. Curr. Biol. 17:1615-1621.

Brigneti, G., Voinnet, O., Li, W. X., Ji, L. H., Ding, S. W., and Baulcombe, D. C. 1998. Viral pathogenicity determinants are suppressors of transgene silencing in Nicotiana benthamiana. EMBO (Eur. Mol. Biol. Organ.) J. 17:6739-6746.

Brigneti, G., Martín-Hernández, A. M., Jin, H., Chen, J., Baulcombe, D. C., Baker, B., and Jones, J. D. G. 2004. Virus-induced gene silencing in Solanum species. Plant J. 39:264-272.

Chirico, N., Vianelli, A., and Belshaw, R. 2010. Why genes overlap in viruses. Proc. R. Soc. B 277:3809-3817.

Chung, B. Y. W., Miller, W. A., Atkins, J. F., and Firth, A. E. 2008. An overlapping essential gene in the Potyviridae. Proc. Natl. Acad. Sci. U.S.A. 105:5897-5902.

Cornelissen, B. J. C., Linthorst, H. J. M., Brederode, F. T., and Bol, J. F. 1986. Analysis of the genome structure of tobacco rattle virus strain PSG. Nucleic Acids Res. 14:2157-2169.

Deblaere, R., Bytebier, B., Degreve, H., Deboeck, F., Schell, J., Vanmontagu, M., and Leemans, J. 1985. Efficient octopine Ti plasmid-derived vectors for Agrobacterium-mediated gene-transfer to plants. Nucleic Acids Res. 13:4777-4788.

Deng, X., Elomaa, P., Nguyen C. X., Hytönen, T., Valkonen, J. P. T., and Teeri, T. H. 2012. Virus-induced gene silencing for Asteraceae-A reverse genetics approach for functional genomics in Gerbera hybrida. Plant Biotechnol. J. 10:970-978.

Du, Z., Xiao, D., Wu, J., Jia, D., Yuan, Z., Liu, Y., Hu, L., Han, Z., Wei, T., Lin, Q., Wu, Z, and Xie, L. H. 2011. p2 of Rice stripe virus (RSV) interacts with OsSGS3 and is a silencing suppressor. Mol. Plant Pathol. 12:808-814

Duan, C. G., Fang, Y. Y., Zhou, B. J., Zhao, J. H., Hou, W. N., Zhu, H., Ding, S. W., and Guo, H. S. 2012. Suppression of Arabidopsis ARGONAUTE1-mediated slicing, transgene-induced RNA silencing, and DNA methylation by distinct domains of the Cucumber mosaic virus $2 \mathrm{~b}$ protein. Plant Cell 24:259-274.

Elmer, J. S., Sunter, G., Gardiner, W. E., Brand, L., Browning, C. K., Bisaro, D. M., and Rogers, S. G. 1988. Agrobacterium-mediated inoculation of plants with tomato golden mosaic virus DNAs. Plant Mol. Biol. 10:225-234.

Ghazala, W., and Varrelmann, M. 2007. Tobacco rattle virus $29 \mathrm{~K}$ movement protein is the elicitor of extreme and hypersensitive-like resistance in two cultivars of Solanum tuberosum. Mol. Plant-Microbe Interact. 20:1396-1405.

Ghazala, W., Waltermann, A., Pilot, R., Winter, S., and Varrelmann, M. 2008. Functional characterization and subcellular localization of the $16 \mathrm{~K}$ cysteine-rich suppressor of gene silencing protein of Tobacco rattle virus. J. Gen. Virol. 89:1748-1758.

Glick, E., Zrachya, A., Levy, Y., Mett, A., Gidoni, D., Belausov, E., Citovsky, V., and Gafni, Y. 2008. Interaction with host SGS3 is required for suppression of RNA silencing by tomato yellow leaf curl virus V2 protein. Proc. Natl. Acad. Sci. U.S.A. 105:157-161. 
González, I., Rakitina, D., Semashko, M., Taliansky, M., Praveen, S., Palukaitis, P., Carr, J.P., Kalinina, N., and Canto, T. 2012. RNA binding is more critical to the suppression of silencing function of Cucumber mosaic virus $2 \mathrm{~b}$ protein than nuclear localization. RNA 18:771-782.

Grimsley, N., Hohn, B., Hohn, T., and Walden, R. 1986. "Agroinfection," an alternative route for viral infection of plants by using the Ti plasmid. Proc. Natl. Acad. Sci. U.S.A. 83:3282-3286.

Guilford, P. J., Ziegler-Graff, V., and Baulcombe, D. C. 1991. Mutation and replacement of the 16-kDa protein gene in RNA-1 of tobacco rattle virus. Virology 182:607-614.

Hamilton, A. J., and Baulcombe, D. C. 1999. A species of small antisense RNA in posttranscriptional gene silencing in plants. Science 286:950-952.

Hamilton, W. D. O., and Baulcombe, D. C. 1989. Infectious RNA produced by in vitro transcription of a full-length tobacco rattle virus RNA-1 cDNA. J. Gen. Virol. 70:963-968.

Hamilton, W. D. O., Boccara, M., Robinson, D. J., and Baulcombe, D. C. 1987. The complete nucleotide sequence of tobacco rattle virus RNA-1. J. Gen. Virol. 68:2563-2575.

Harvey, J. J. W., Lewsey, M. G., Patel, K., Westwood, J., Heimstädt, S., Carr, J. P., and Baulcombe, D. C. 2011. An antiviral defense role of AGO2 in plants. PLoS ONE 6:e14639. Published online.

Haseloff, J., Siemering, K. R., Prasher, D. C., and Hodge, S. 1997. Removal of a cryptic intron and subcellular localization of green fluorescent protein are required to mark transgenic Arabidopsis plants brightly. Proc. Natl. Acad. Sci. U.S.A. 94:2122-2127.

Hernández, C., Visser, P. B., Brown, D. J. F., and Bol, J. F. 1997. Transmission of tobacco rattle virus isolate $\mathrm{PpK} 20$ by its nematode vector requires one of the two non-structural genes in the viral RNA 2. J. Gen. Virol. 78:465-467.

Johansen, L. K., and Carrington, J. C. 2001. Silencing on the spot. Induction and suppression of RNA silencing in the Agrobacterium-mediated transient expression system. Plant Physiol. 126:930-938.

Kapila, J., Rycke, R. D., Montagu, M. V., and Angenon, G. 1997. An Agrobacterium-mediated transient gene expression system for intact leaves. Plant Sci. 122:101-108.

Kasschau, K. D., Fahlgren, N., Chapman, E. J., Sullivan, C. M., Cumbie, J. S., Givan, S. A., and Carrington, J. C. 2007. Genome-wide profiling and analysis of Arabidopsis siRNAs. PLoS Biol. 5:e57. Published online.

Kreuze, J. F., Savenkov, E. I., Cuellar, W., Li, X. D., and Valkonen, J. P. T. 2005. Viral class 1 RNase III involved in suppression of RNA silencing. J. Virol. 79:7227-7238

Kumagai, M. H., Donson, J., Dellacioppa, G., Harvey, D., Hanley, K., and Grill, L. K. 1995. Cytoplasmic inhibition of carotenoid biosynthesis with virus-derived RNA. Proc. Natl. Acad. Sci. U.S.A. 92:1679-1683.

Liu, D. H., Robinson, D. J., Duncan, G. H., and Harrison, B. D. 1991. Nuclear location of the $16 \mathrm{~K}$ nonstructural protein of tobacco rattle virus. $\mathrm{J}$. Gen. Virol. 72:1811-1817.

Liu, H., Reavy, B., Swanson, M., and MacFarlane, S. A. 2002a. Functional replacement of the Tobacco rattle virus cysteine-rich protein by pathogenicity proteins from unrelated plant viruses. Virology 298:232-239.

Liu, Y. L., Schiff, M., and Dinesh-Kumar, S. P. 2002b. Virus-induced gene silencing in tomato. Plant J. 31:777-786.

Liu, Y. L., Schiff, M., Marathe, R., and Dinesh-Kumar, S. P. 2002c. Tobacco Rarl, EDS1 and NPR1/NIM1 like genes are required for N-mediated resistance to Tobacco mosaic virus. Plant J. 30:415-429.

Llave, C., Kasschau, K. D., and Carrington, J. C. 2000. Virus-encoded suppressor of posttranscriptional gene silencing targets a maintenance step in the silencing pathway. Proc. Natl. Acad. Sci. U.S.A. 97:1340113406.

MacFarlane, S. A. 1999. Molecular biology of the tobraviruses. J. Gen. Virol. 80:2799-2807.

MacFarlane, S. A. 2010. Tobraviruses_plant pathogens and tools for biotechnology. Mol. Plant Pathol. 11:577-583.

MacFarlane, S. A., and Popovich, A. H. 2000. Efficient expression of foreign proteins in roots from tobravirus vectors. Virology 267:29-35.

MacFarlane, S. A., Vassilakos, N., and Brown, D. J. F. 1999. Similarities in the genome organization of tobacco rattle virus and pea early-browning virus isolates that are transmitted by the same vector nematode. J. Gen. Virol. 80:273-276.

Martín-Hernández, A. M., and Baulcombe, D. C. 2008. Tobacco rattle virus 16-kilodalton protein encodes a suppressor of RNA silencing that allows transient viral entry in meristems. J. Virol. 82:4064-4071.

Martínez-Priego, L., Donaire, L., Barajas, D., and Llave, C. 2008. Silencing suppressor activity of the Tobacco rattle virus-encoded 16-kDa protein and interference with endogenous small RNA-guided regulatory pathways. Virology 376:346-356.

Matzke, M. A., and Birchler, J. A. 2005. RNAi-mediated pathways in the nucleus. Nat. Rev. Genet. 6:24-35.
McFadden, N., Bailey, D., Carrara, G., Benson, A., Chaudhry Y, Shortland, A., Heeney, J., Yarovinsky, F., Simmonds, P., Macdonald, A., and Goodfellow, I. 2011. Norovirus regulation of the innate immune response and apoptosis occurs via the product of the alternative open reading frame 4. PLoS Pathog. 7:e1002413. Published online.

Pall, G. S., and Hamilton, A. J. 2008. Improved Northern blot method for enhanced detection of small RNA. Nat. Protocols 3:1077-1084.

Peart, J. R., Cook, G., Feys, B. J., Parker, J. E., and Baulcombe, D. C. 2002. An EDS1 orthologue is required for $N$-mediated resistance against Tobacco mosaic virus. Plant J. 29:569-579.

Pfaffl, M. W. 2001. A new mathematical model for relative quantification in real-time RT-PCR. Nucleic Acids Res. 29:e45.

Qu, F. 2010. Antiviral role of plant-encoded RNA-dependent RNA polymerases revisited with deep sequencing of small interfering RNAs of virus origin. Mol. Plant-Microbe Interact. 23:1248-1252.

Rajamäki, M. L., and Valkonen, J. P. T. 2009. Control of nuclear and nucleolar localization of nuclear inclusion protein a of picorna-like Potato virus A in Nicotiana species. Plant Cell 21:2485-2502.

Rajamäki, M. L., Kelloniemi, J., Alminaite, A., Kekarainen, T. Rabenstein, F., and Valkonen, J. P. T. 2005. A novel insertion site inside the potyvirus $\mathrm{P} 1$ cistron allows expression of heterologous proteins and suggests some P1 functions. Virology 342:88-101.

Rancurel, C., Khosravi, M., Dunker, A. K., Romero, P., and Karlin, D. 2009. Overlapping genes produce proteins with unusual sequence properties and offer insight into de novo protein creation. J. Virol. 83:10719-10736.

Ratcliff, F., Martin-Hernandez, A. M., and Baulcombe, D. C. 2001. Tobacco rattle virus as a vector for analysis of gene function by silencing. Plant J. 25:237-245.

Reavy, B., Dawson, S., Canto, T., and MacFarlane, S. A. 2004. Heterologous expression of plant virus genes that suppress post-transcriptional gene silencing results in suppression of RNA interference in Drosophila cells. BMC Biotechnol. 4:18.

Robinson., D. J., and Harrison, B. D. 1989. Tobacco rattle virus. Descriptions of Plant Viruses No. 346. Association of Applied Biologists, Warwick, U.K.

Ruiz, M. T., Voinnet, O., and Baulcombe, D. C. 1998. Initiation and maintenance of virus-induced gene silencing. Plant Cell 10:937-946.

Savenkov, E. I., and Valkonen, J. P. T. 2001. Potyviral helper-component proteinase expressed in transgenic plants enhances titers of Potato leaf roll virus but does not alleviate its phloem limitation. Virology 283:285-293

Senthil-Kumar, M., and Mysore, K. S. 2011. New dimensions for VIGS in plant functional genomics. Trends Plant Sci. 16:656-665.

Shew, H. D., and Lucas, G. B. 1991. Compendium of Tobacco Diseases American Phytopathological Society Press, St. Paul, MN, U.S.A.

Shivprasad, S., Pogue, G. P., Lewandowski, D. J., Hidalgo, J., Donson, J., Grill, L. K., and Dawson, W. O. 1999. Heterologous sequences greatly affect foreign gene expression in tobacco mosaic virus-based vectors. Virology 255:312-323.

Swanson, M., Barker, H., and MacFarlane, S. A. 2002. Rapid vascular movement of tobraviruses does not require coat protein: Evidence from mutated and wild-type viruses. Ann. Appl. Biol. 141:259-266.

Sztuba-Solinska, J., Urbanowicz, A., Figlerowicz, M., and Bujarski, J. J. 2011. RNA-RNA recombination in plant virus replication and evolution. Annu. Rev. Phytopathol. 49:415-443.

Taliansky, M. E., Brown, J. W. S., Rajamäki, M. L., Valkonen, J. P. T., and Kalinina, N. O. 2010. Involvement of the plant nucleolus in virus and viroid infections: Parallels with animal pathosystems. Adv. Virus Res. 77:119-158.

Valentine, T., Shaw, J., Blok, V. C., Phillips, M. S., Oparka, K. J., and Lacomme, C. 2004. Efficient virus-induced gene silencing in roots using a modified Tobacco rattle virus vector. Plant Physiol. 136:3999-4009.

Voinnet, O., Vain, P., Angell, S., and Baulcombe, D. C. 1998. Systemic spread of sequence-specific transgene RNA degradation in plants is initiated by localized introduction of ectopic promoterless DNA. Cell 95:177-187.

Vuorinen, A. L., Kelloniemi, J., and Valkonen, J. P. T. 2011. Why do viruses need phloem for systemic invasion of plants? Plant Sci. 181:355-363.

Wu, Q., Wang, X., and Ding, S. W. 2010. Viral suppressors of RNA-based viral immunity: Host targets. Cell Host Microbe 8:12-15.

Xie, Z., Johansen, L. K., Gustafson, A. M., Kasschau, K. D., Lellis, A. D., Zilberman, D., Jacobsen, S. E., and Carrington, J. C. 2004. Genetic and functional diversification of small RNA pathways in plants. PLoS Biol. 2:e104. Published online

Ziegler-Graff, V., Guilford, P. J., and Baulcombe, D. C. 1991. Tobacco rattle virus RNA-1 29K gene-product potentiates viral movement and also affects symptom induction in tobacco. Virology 182:145-155. 